Revista de la red interuniversitaria de estudios sobre las literaturas rioplatenses contemporáneas en Francia

$9 \mid 2013$

Homenaje a Ana María Barrenechea

\title{
La Camila de Camilo Henríquez o el dilema corneliano de la minoría criolla
}

Dardo Scavino

(2) OpenEdition

Journals

Edición electrónica

URL: http://journals.openedition.org/lirico/1171

DOI: $10.4000 /$ lirico. 1171

ISSN: 2262-8339

Editor

Réseau interuniversitaire d'étude des littératures contemporaines du Río de la Plata

Referencia electrónica

Dardo Scavino, "La Camila de Camilo Henríquez o el dilema corneliano de la minoría criolla »,

Cuadernos LIRICO [En línea], 9 | 2013, Puesto en línea el 01 septiembre 2013, consultado el 19 abril

2019. URL : http://journals.openedition.org/lirico/1171 ; DOI : 10.4000/lirico.1171

Este documento fue generado automáticamente el 19 abril 2019.

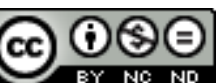

Cuadernos LIRICO está distribuido bajo una Licencia Creative Commons Atribución-NoComercialSinDerivar 4.0 Internacional. 


\title{
La Camila de Camilo Henríquez o el dilema corneliano de la minoría criolla
}

\author{
Dardo Scavino
}

\section{Introducción}

En octubre de 1817 la imprenta porteña del señor Diego Benavente publicó La Camila o la Patriota de Sud-América del fraile Camilo Henríquez, con el siguiente subtítulo: Drama sentimental en cuatro actos. Henríquez era un cura revolucionario, miembro de la orden de los Ministros de los Enfermos Agonizantes, o "Frailes de la Buena Muerte", que había llegado al Río de la Plata, como muchos de sus compatriotas, después de la derrota de Rancagua en octubre de 1814. El sacerdote había dirigido en su país el semanario $L a$ Aurora de Chile a lo largo de dos años y había asumido en Buenos Aires la conducción de otro periódico independentista, El Censor, atreviéndose a redactar además su primer texto dramático para que se representara en la capital rioplatense con el auspicio de la flamante Sociedad del Buen Gusto del Teatro.

2 Fundada por un decreto del Director Supremo, Juan Martín de Pueyrredón, el 28 de junio de 1817, esta institución se proponía difundir los valores revolucionarios a través del arte escénico y contaba entre sus fundadores con las firmas de Manuel Belgrano, Vicente López y Valentín Gómez (Durán Cerda 1960 : 231, Villegas Morales 2005 : 108). El propio Henríquez saludaría con entusiasmo la creación de la Sociedad así como su primera puesta en escena, Cornelia Bororquia, una pieza anónima sobre las atrocidades perpetradas por el Tribunal de la Inquisición que Mariano Bosch (1910: 54) le atribuiría más tarde al actor Luis Ambrosio Morante, autor de un drama sobre Túpac Amaru y, según parece, de Siripo y Yara, versión revolucionaria del Siripo de Lavardén. Lo más probable, sin embargo, es que esta Cornelia Bororquia haya sido una adaptación -el libreto se extravió- de la novela epistolar homónima del fraile español Luis Gutiérrez, ejecutado en 1809 por orden de la Junta de Sevilla. 
Cuando los responsables de la Sociedad del Buen Gusto se negaron a poner en escena La Camila, Henríquez sugirió que la decisión obedecía al apocamiento político de sus directivos (Aisemberg 2005 : 163) aunque los únicos pasajes de su texto que hubiesen podido motivar este rechazo -una denuncia velada de ese mismo tribunal inquisitorial que había detenido e interrogado al fraile en 1809- se inscribían en la huella abierta por Cornelia Bororquia, una obra que Pueyrredón se había negado a prohibir a pesar de las presiones del episcopado. El primer biógrafo de Camilo Henríquez, Miguel Luis Amunátegui, estimaba que las razones de la exclusión tuvieron que ser más bien estéticas : la obra "no dejó entonces ni deja ahora buena impresión" porque "había en su argumento muchas disertaciones y poquísima acción" y porque finalmente la heroína, Camila Shkinere, "era el mismísimo padre Henríquez con faldas" (1889 : 14). Y es verdad que el fraile transandino no se mostró muy discreto con su travestismo teatral : como si no le hubiese bastado con endosarle su propio nombre a la protagonista del drama, le yuxtapuso un apellido que no era sino un anagrama de Henríquez (Shkinere, Henrikes).

El fraile tenía una concepción particular de la representación teatral que explicaría en parte esas opciones. Él pensaba que si amábamos, en general, la ilusión escénica, se debía a que le "presta encantos a la verdad":

La voz de la filosofía es demasiado árida para muchos; conviene suavizarla, amenizarla con las gracias de la musas. La filosofía, pues, habló desde el teatro en lenguaje agradable y gracioso; y el pueblo dócil oyó sus sentencias con placer. Por este medio, la ilustración vino a hacerse general; se minaron los cimientos del despotismo de todo género; la opinión, el pensamiento, la prensa, rompieron sus grillos; fantasmas odiosos fueron a tierra; adoptaron los gobiernos una conducta más liberal; se prepararon las grandes reformas que hemos visto, y que veremos después. (Amunátegui 1889 : 303)

Sólo que Henríquez habría confundido el teatro didáctico, o subordinado a una teoría filosófica (Badiou 1998: 10), con la exposición de opiniones filosóficas bajo una forma teatral, y esto explicaría la exclusión de sus obras de una sociedad que no se proponía solamente educar al pueblo en "la virtud y el patriotismo" sino también "irle formando el gusto" (Aisemberg 2005 : 160).

Pero si Amunátegui tenía sin duda razón en lo referente a los infortunios estéticos de la composición teatral del fraile (Urquiza Amandoz 1977 : 23), se equivocaba en insinuar que el "drama sentimental" era apenas un pretexto para intercalar disertaciones políticas y morales. Los sentimientos amorosos no pueden desvincularse aquí del problema de las alianzas matrimoniales y políticas entre las diferentes "familias" de las sociedades virreinales. Y hasta podríamos conjeturar que La Camila es un drama político porque es, precisamente, un drama sentimental, una manera de exponer la cuestión de las alianzas políticas de ese período histórico a través de las alianzas conyugales.

\section{Horacios y Curiacios}

7 La Camila comienza evocando un episodio ocurrido durante la estadía de Camilo Henríquez en Quito, origen de la célebre declaración de "guerra a muerte" contra los españoles proferida por Simón Bolívar. El 24 de octubre de 1809 las tropas virreinales al mando del conde Ruiz de Castilla obtuvieron la rendición de los miembros de la primera junta provisional de gobierno que había sustituido al virrey el 10 de agosto (Rodríguez Castelo 2010: 88). Un año más tarde, el 2 de agosto de 1810, una asonada popular 
intentaba liberar a los patriotas que habían sido condenados a muerte en un proceso organizado sobre la base de testimonios dudosos y confesiones obtenidas con torturas. Los soldados iniciaron la represión con el asesinato de los presos, dejando a continuación un saldo de entre 200 y 300 muertos entre los amotinados. Creyendo que su esposo Diego había muerto en la masacre, Camila abandona la ciudad en compañía de sus padres para refugiarse en una aldea omagua situada a orillas del Marañón, en plena selva amazónica. Ella no sabe que Diego había logrado escaparse ni que se encontraba, casualmente, en ese mismo poblado, donde el Cacique lo había nombrado primer ministro de su gobierno jeffersoniano. Para poner a prueba la fidelidad de la joven, el jefe omagua le oculta la presencia del marido y le hace creer que las autoridades españolas reclamaban a los prófugos. Les explica a los refugiados que está obligado a entregarlos, a menos que la joven acepte casarse con el primer ministro de la aldea, lo que la convertiría a ella y a su familia en omaguas por alianza. Camila, quien guarda la secreta esperanza de reencontrar a su esposo e ignora la verdadera identidad del ministro, se niega a darle su mano. El Cacique le reprocha entonces que las criollas prefieran casarse con españoles, enemigos de la patria, en lugar de hacerlo con patriotas "americanos", lo que demuestra hasta qué punto desprecian a los indígenas, como cuando se mostraron totalmente indiferentes ante el destino de Túpac Amaru y los suyos. Al final, y una vez comprobada sin el menor margen de duda la fidelidad a su marido, y a su patria, el Cacique llama a su ministro para que Camila descubra, sorprendida y feliz, a Diego.

El argumento no presenta mucho interés ya que el espectador advierte muy pronto cuál va a ser la solución y sólo le resta esperar que Camila la descubra. El único personaje, además, que podría interpretar el papel del anti-héroe frente a la unánime probidad del resto de los personajes es el Cacique, quien en realidad sólo finge oponerse a Camila para probar su lealtad (el propio Henríquez sugiere incluso que su manera de proceder guarda ciertas similitudes con la divina providencia). Los únicos auténticos adversarios, los españoles, no aparecen nunca en escena, y toda la acción se desarrolla entre patriotas. De hecho, Henríquez sólo dilata el desenlace para multiplicar las intervenciones de sus diversos alter egos -el Cacique, su cuñado, la propia Camila-, quienes se limitan a proferir opiniones que podemos encontrar en sus artículos periodísticos, como cuando el Cacique le muestra a Diego un escrito de Camila en el que ésta propone el incentivo de la inmigración para desarrollar las nuevas repúblicas.

9 Hay sin embargo un detalle que suele pasarse por alto. Justo antes de que el Cacique le revele a Diego que Camila se encuentra con vida y, además, en la misma aldea, el joven estaba recordando que su mujer solía cantar un aria de Cimarosa "con una expresión singular" (1817: 32$)$. El aria se intitula "Quelle pupille tenere" y forma parte de la ópera Los Horacios y los Curiacios que el músico napolitano compuso con libreto de Antonio Simeone Sografi. Esta obra se inspiraba en la célebre tragedia de Corneille, Horacio, versión teatral, a su vez, de una antiquísima leyenda latina recogida por Tito Livio : cuando el único sobreviviente de los tres Horacios regresó a Roma trayendo los cadáveres de sus tres enemigos, los trillizos Curiacios, su hermana Camila prorrumpió en llanto porque uno de los guerreros albanos era su propio marido. Furioso por esta reacción, Horacio la asesina. A través del enfrentamiento entre los Horacios y los Curiacios, la leyenda evocaba un hecho histórico : el triunfo de Roma sobre su vecina Alba Longa. Pero también, claro está, un interrogante antropológico : ¿a qué familia pertenece una mujer?

Unos años después del escándalo provocado por El Cid, Corneille volvería a poner en escena el dilema trágico entre el honor y el amor. La Camila corneliana se hallaba dividida 
entre la filiación y el matrimonio o entre la familia de sangre y la familia por alianza, y algo semejante ocurre con la heroína de la ópera de Cimarosa aunque el napolitano no la hubiese llamado Camila sino -para evocar su gens- Horacia. En la ópera, es cierto, el aria "Quelle pupille tenere" no es cantada por Horacia sino por su marido, Curiacio. Pero este deslizamiento tal vez tenga una explicación : como el napolitano tuvo la ocurrencia de componerla para el soprano castrato Girolamo Crescentini, la interpretaron a continuación las sopranos femeninas, y es lo que sucedió durante la velada en que la escuchó Camilo Henríquez, justo después del estreno de Cornelia Bororquia, en el teatro Coliseo y acompañada por un pianoforte (Bosch 1905 : 16). Es muy probable que el fraile haya pensado entonces que este aria "patriótica", muy a tono con el fervor republicano de los partidarios de la Revolución francesa, entre quienes se encontraban Sografi y Cimarosa, hubiera sido cantada, en la ópera, por el personaje de Horacia, es decir, Camila :

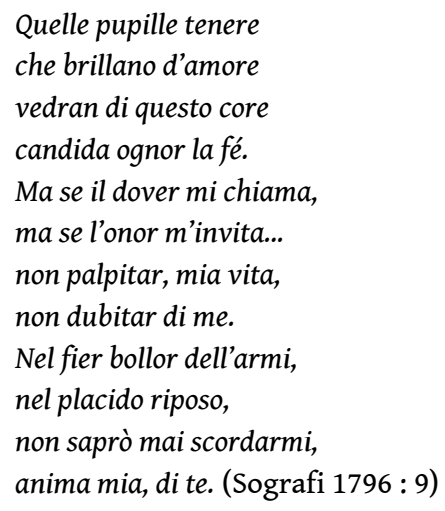

11 Sugiriendo entonces que su Camila interpretaba "con una expresión singular" estos versos de Sografi, Henríquez estaba remitiendo al espectador a la Camila corneliana y su trágico dilema entre la fidelidad a la sangre o la alianza. Hay, sin embargo, una diferencia fundamental entre ambos personajes: la Camila criolla opta por mantenerse leal a la alianza en detrimento de la sangre, pero ésta es, en su caso, la decisión "patriótica", ya que la patria no se confunde aquí con la gens española sino con la natio americana, familia de su marido. La elección del nombre Camila, en todo caso, obedecía a dos motivos : se trataba, es cierto, de un alter ego femenino del fraile, que interpreta el aria de un castrato, pero también de una alusión a la leyenda sobre los orígenes de la república romana.

Que este dilema corneliano sea, a la vez, femenino, tiene que ver con el estatuto de la alianza en las sociedades patrilineales donde los hombres intercambian -y no a la inversa- a las mujeres. Son ellas quienes poseen dos apellidos, quienes pertenecen, por la sangre, a la familia de su padre y, por la alianza, a la casa del marido, de modo que están obligadas a escoger, cuando un conflicto estalla entre ambos grupos, a cuál de ellos van a mantenerse leales. Eligiendo la familia por alianza, o política, rompiendo con sus orígenes españoles y amando a un americano, el personaje de Camila Shkinere está encarnando la opción fundacional de las repúblicas criollas, en las que el ius sanguinis virreinal va a verse sustituido, hasta nuestros días, por el ius soli.

13 Las resonancias del apellido, Shkinere, nos sugieren incluso que su esposo Diego podría pertenecer a un linaje indígena. Henríquez no es nunca claro a este respecto, pero cuando el Cacique le propone a Camila casarse con su ministro -escondiéndole su identidad-, le asegura que se convertiría así en omagua a través del matrimonio. Y cuando la muchacha se niega a hacerlo por fidelidad a su marido, el Cacique le suelta esta diatriba : 
CACIQUE. -Esa es vuestra soberbia, ese es el alto desprecio con que nos tratáis. Las jóvenes de Sud-América menosprecian generalmente a todos los americanos. Desde el principio prefirieron para esposos a los españoles. Guardan para los españoles sus gracias, esas gracias delicadas, sublimes, divinas, que recibieron del cielo para nuestra felicidad. Ellas quisieran que reinasen eternamente los españoles, para reinar con ellos. Ellas desean que permanezca la patria en perpetua servidumbre, seguras del imperio que han de ejercer sobre sus débiles amantes. Ellas verían con placer la opresión universal del país; oirían con alegría los horrendos decretos pronunciados contra los americanos por sus inhumanos esposos. Así educan a sus hijos en el amor de la tiranía y oponen obstáculos a la libertad. ¡Oh! ¡Qué furor! ¡Qué indignación! ¡Las hijas de América abrazarán a nuestros verdugos y huirán con desdén de los brazos robustos de los héroes de la patria! Americana degradada, vuestra presencia me avergüenza. Ojalá hubieseis nacido a la otra parte del mar, entre los tiranos, para que no deshonraseis a la patria con vuestros sentimientos. (Henríquez 1817 : 22)

14 El propio Cacique vincula este desinterés de las jóvenes y sus familias criollas hacia los eventuales novios indígenas -incluso aquellos procedentes de la prestigiosa nobleza incaica- con la ausencia de solidaridad de los españoles americanos y las poblaciones autóctonas. Cuando la familia de Camila le solicita su hospitalidad, el Cacique le reprocha la indiferencia de los quiteños para con un pariente de Túpac Amaru II :

CACIQUE.-Y ¿qué hospitalidad halló entre ustedes aquel pariente del Muy Alto y Muy Poderoso Príncipe José Gabriel de Túpac Amaru cuando huyendo de la horrenda carnicería, que hacían los realistas en su país, buscó en el vuestro un asilo infeliz y obscuro ? Vosotros lo asesinasteis en la cárcel en el silencio de la noche.

D. JOSE. - ¡Nosotros! El presidente de Quito y los ministros de su audiencia cometieron esa maldad.

CACIQUE. -Visteis tranquilos la muerte del desventurado príncipe, y no hicisteis en su defensa movimiento alguno.

D. JOSE. -Estábamos bajo la espada del despotismo. La España era respetable entonces, en el reinado de Carlos III.

CACIQUE. -Visteis correr la sangre del alto príncipe, y no derramasteis una lágrima. Divididos entre vosotros mismos, alimentando odios y envidias, despreciándoos recíprocamente; insensibles, desnaturalizados, visteis con fría indiferencia el trágico fin de un americano ilustre. Tal vez disteis elogios a la crueldad de sus verdugos.

DOÑA MARGARITA. -Hasta ahora se habla en Quito con horror de aquella bárbara atrocidad. (Henríquez $1817: 21$ )

\section{Un fervor contradictorio}

Como lo sugiere el Cacique, los criollos también se encontraban con este dilema femenino y corneliano, ya que ellos también tenían dos nombres : como "españoles americanos", se hallaban tensionados entre su familia de sangre, española, y su familia por alianza, americana. Por un lado, en efecto, reivindicaban su origen hispano, y reclamaban los privilegios propios de este linaje, como cuando otro Camilo, el neogranadino Torres Tenorio, le exige a la mencionada Junta de Sevilla que no haga ninguna diferencia entre los "descendientes de don Pelayo" de un lado y otro del mar (Torres Tenorio 1979: 29). Y en este aspecto, los criollos no cesaban de recordarles a sus pares metropolitanos que sus ancestros habían conquistado los territorios americanos en nombre de los reyes españoles y que éstos les habían retribuido sus esfuerzos concediéndoles a ellos, y a su descendencia, el gobierno de esas tierras, concesión que los posteriores monarcas no habían respetado, a tal punto que los Borbones, por temor al creciente poder de las élites 
criollas, habían decidido remplazar a los virreyes, corregidores $u$ oidores nativos por enviados metropolitanos. El propio Camilo Henríquez recordaba en uno de sus artículos de La Aurora de Chile que la metrópoli, en un principio, había usado

[D]e una misma conducta para con los Españoles habitantes de América, sin hacer una distinción sensible entre los que nacieron de esta o la otra parte del mar. Así, los Señores Armendaris, Vega, Sandonas, y en nuestros días los Señores Moscoso, Carbajal, Aldai, Maran, Cuero Perez, Ahiles, Reguera, Gonzales se han visto ocupar los empleos mas distinguidos de la Iglesia y del Estado. Así pues españoles europeos y americanos fueron a sus ojos una misma familia, revestida de unos mismos derechos, y sujeta al influjo a veces benigno, a veces aciago y opresor de los varios ministros de los reyes. En unos y otros o gozaron de una misma consideración, o padecieron un mismo olvido los talentos, el mérito y las virtudes. A unos y otros fueron igualmente ventajosas las riquezas. (Henríquez 1903 : 77)

Pero por otra parte, los criollos ponían en entredicho el derecho de conquista invocado por los reyes españoles para legitimar la posesión de esas tierras y, como americanos, se mostraban solidarios con las poblaciones autóctonas, incautadas y masacradas, viendo en las revoluciones de la independencia una revancha de los primitivos pobladores contra los invasores ultramarinos. Henríquez mismo había escrito un poema consagrado a celebrar la primera junta de gobierno chilena en donde sólo invocaba el presunto derecho de conquista para negar su legitimidad y denunciar la usurpación española :

¿Y el célebre derecho de conquista?

¿Puede ser un derecho de violencia?

¡Llamar derecho al robo, al exterminio!

Derecho es de ladrones y de fieras. (Henríquez 1903 : 144)

17 Pero en la estrofa siguiente el propio fraile añadía :

Si da derechos la conquista, somos

Solo nosotros dueños de estas tierras,

Pues todos somos, sin haber disputa,

De los conquistadores descendencia. (1903:144)

El propio Henríquez glosaba este sinuoso argumento en un artículo de La Aurora de Chile :

No quiero subir a la conquista, y empeñar los argumentos que demuestran que la fuerza y la violencia nunca autorizaron la usurpación de lo que era ajeno : cuando todos saben que el dominio no se adquiere sino por un pacto con qué el propietario legalmente lo transfiera : y los Pueblos de Chile no sabemos que hubiesen celebrado semejante contrato con sus Conquistadores, cuyos derechos (si tuviesen algunos) nos corresponderían como a su descendencia... (1903: 161)

19 En boca de los criollos, el pronombre personal nosotros tenía, en efecto, dos extensiones diferentes : a veces, como aquí, abarcaba solamente a los españoles nacidos en América, quienes se presentaban ante las autoridades imperiales como los descendientes de los conquistadores -sin importar si individualmente lo eran- y que, por este motivo, se consideraban con derecho a gozar de las prelaciones estipuladas en las capitulaciones firmadas por los Reyes Católicos y Carlos V; pero a veces, ese pronombre abrazaba también a todos los americanos, y sobre todo a los autóctonos, en una vasta coalición popular contra el "usurpador español" (Scavino 2010 : 77).

Un amigo cordobés de Henríquez, el deán Gregorio Funes, también había jugado con esta vacilación del gentilicio americano en su Ensayo de la historia civil del Paraguay, Buenos-Ayres y Tucumán, aparecido un año antes de La Camila. El sacerdote recordaba, por un lado, que los conquistadores eran "nuestros mayores" y que "nos adquirieron la herencia que gozamos", y lo hacía para denunciar a esos "empleados opulentos y voluptuosos" de la 
administración colonial, que casi nunca eran "americanos" (Funes 1816: 306). Y sin embargo se trataba, a su entender, de empleos que "los conquistadores creían haber comprado con su sangre", para ellos y sus herederos (1816: 296). Pero cuando cuenta cómo esos mismos conquistadores, o sus descendientes, sofocaban ciertas rebeliones indígenas, el propio Funes comenta: "En el concepto de los tiranos, los pasos hacia la libertad son una rebelión" (1816: 157). El prelado llegaba incluso a convertir esta resistencia de los pueblos originarios en una figura premonitoria de las guerras de la independencia, como cuando recordaba que los Quilmes "se resolvieron a no abandonar su libertad al arbitrio de unas gentes que pretendían prostituir su existencia al yugo de una obediencia servil" (1816:151).

En sus Noticias secretas de América, escritas en 1738, Antonio de Ulloa y Jorge Juan y Santicilia ya habían observado que los españoles americanos detestaban a sus pares europeos y que, por este motivo, se decían hermanos de los americanos indígenas. Sin embargo, añadían, "de este extremo pasan los criollos a otro, no menos malo" (Ulloa 1918: 99), porque cortejaban y obsequiaban a los metropolitanos como si hubiesen sido todos nobles, a tal punto que las familias preferían que sus hijas se casaran con individuos oriundos de la península aunque fuesen de oscuros linajes. Esta constatación de los espías de Carlos III sería corroborada por algunos historiadores del período virreinal, como cuando Daisy Rípodas Ardanaz explica que los peninsulares no eran solamente los futuros yernos predilectos de las familias criollas sino también los esposos preferidos por las niñas de la casa, aun cuando estos españoles no provinieran de la aristocracia (1977 : 143). Raros eran de cualquier modo los casos en que las mujeres elegían a sus maridos fuera de la élite blanca, y cuando lo hacían, esta "desigualdad" racial se convertía en uno de los principales motivos de divorcio admitidos por la corona : después de la Real Pragmática de 1778 los propios padres podrían reclamar el divorcio ante la justicia alegando que esa "desigualdad" lesionaba los intereses de sus hijos (Fuentes Barragán 2012 ; Lavallé 2008; Senor 2005). De modo que a través de este decreto real, los monarcas españoles se proponían limitar oficialmente las alianzas entre minorías americanas, y lo hacían recurriendo a los (como se los llama) prejuicios paternos.

Cuando Henríquez evoca la ópera de Cimarosa y la tragedia de Corneille, no está haciendo alusión a una contradicción de Camila Shkinere sino, como lo sugiere el Cacique, a la de esas otras Camilas criollas, o hispano-americanas, a través de las cuales las familias urdían sus alianzas matrimoniales y, como consecuencia, políticas con sus pares peninsulares, prosiguiendo así con la tradición endogámica del clan hispano. Cuando el Cacique increpa a Camila y a su madre lamentando que no hubieran "nacido a la otra parte del mar, entre los tiranos", para que no hubiesen deshonrado "la patria con vuestros sentimientos" (1817 : 23), está sugiriendo que las preferencias conyugales de las jóvenes criollas solían excluir a los indígenas, poniéndose así en contradicción con las alianzas políticas patrióticas del período independentista.

\section{Alianza y hegemonía}

No era la primera vez que Henríquez abordaba esta cuestión. Unos años antes, en un artículo de La Aurora de Chile consagrado a los araucanos -quienes todavía no formaban parte de este país y se mostraban incluso renuentes a apoyar la revolución de los criollosel fraile se refería a la necesidad de estrechar "nuestras familias con las suyas" : sólo así, explicaba, los indios lograrían persuadirse de que "los reconocemos por iguales a 
nosotros, que nada hay en nosotros que nos haga superiores" dado que "la consanguinidad es sin duda el lazo más pronto y más fuerte" y "reduce a una sola familia los extranjeros y los naturales del país" (Henríquez 1903: 51). Henríquez, quien unos meses antes lamentaba que la monarquía hubiese separado a los españoles nacidos en ambas márgenes del Atlántico, convirtiendo "en enemigos a muchos miembros de nuestra gran familia" (1903 : 30), proponía ahora que los españoles americanos y los indios formasen una nueva familia o que consolidaran sus alianzas a través de los matrimonios.

Esta igualdad tenía, a pesar de todo, una serie de bemoles. Porque Henríquez ponía una condición para que ambas "familias" estrechasen estos lazos: no debía haber "disonancia", a su entender, "en la educación, religión, modales y costumbres" (1903 : 51). Lo que no significaba, por supuesto, que los criollos tuvieran que adoptar la educación, la religión, los modales y las costumbres de las poblaciones autóctonas sino a la inversa. De modo que esta nueva alianza con vistas a combatir a ese enemigo común que, según sus propios decires, había usurpado el territorio americano tras la llegada de Colón -esa unión con vistas a invertir, por decirlo así, las nefastas consecuencias de la conquista española-, constituía también una continuación de la conquista por otros medios.

A través de esta alianza los indígenas comprenderían entonces que los "conocimientos de los pueblos cultos eran muy necesarios para mejorar su suerte" (1903: 51). Porque los indios, aseguraba, "están en estado de considerarse como una nación nueva y, por consiguiente, fácil y dispuesta para ser ilustrada", como ocurre con los jóvenes que no tienen todavía un patrimonio cultural que sea preciso erradicar (1903 : 51). Los araucanos no tenían una cultura distinta : no tenían, a sus ojos, absolutamente ninguna. De modo que los indígenas educados por los criollos les transmitirían a sus semejantes las "ideas exactas sobre la religión, la moral, la legislación, el comercio, la industria, la agricultura”, "comunicarían sus conocimientos, los adelantarían, iluminarían su país" (1903 : 51). Y así se habría "dado un gran paso al grandioso designio de que todos nuestros compatriotas, indios y españoles, formen una sola familia, sujeta a unas mismas leyes y a un solo gobierno":

¡Cuantos infelices volarán a aquella región con las artes, la industria, las luces! Que perspectiva tan risueña, y consoladora: el Sud y el Norte del nuevo mundo igualmente venturosos ; la paz, las artes, las ciencias de la Pensilvania trasladadas al suelo Araucano, constituido en asilo de la libertad, que huye de la Europa con las virtudes pacíficas; un espacio de cuatro mil leguas cuadradas, bello, y prodigiosamente fecundo poblándose de hombres útiles bajo los auspicios de la razón, y de un Gobierno justo, e iluminado, que consuele a la especie humana de sus largos martirios, persecuciones y amarguras ! (1903:51)

Dos condiciones debían reunirse entonces para que un nuevo pueblo existiera : en primer lugar, una unión entre dos familias (alianza que se hace, por lo general, en contra de una tercera) ; en segundo lugar, un sometimiento de una de las familias de la alianza a los valores y las costumbres de la otra. Alianza y hegemonía se convierten así en las palabras clave -Henríquez no es el único en plantear esto- para quien desee comprender la constitución política, y matrimonial, de un pueblo nuevo.

En La Camila, justamente, Henríquez imagina una tribu omagua en la que su proyecto americano -algunos hablan incluso de utopía (Keeding 2009 : 190)- se habría llevado a cabo finalmente. Hasta 1767, en efecto, los omaguas de esa región habían formado parte de las misiones del imperio jesuítico, y el padre de Camila recuerda este período en una de sus alocuciones : 
D. JOSE. -Los jesuitas señalaron en estos rudos países su celo apostólico y su beneficencia. Ellos ganaron con beneficios el corazón de las tribus salvajes. Formaron muchas poblaciones. Les hicieron conocer el pudor y la decencia. ¡Qué respetables aparecen a la vista del hombre pensador aquellos extranjeros, que enseñaron a estos pobrecitos a labrar la tierra ; a amar a sus esposas, a criar sus hijos, como se hace en los pueblos civilizados, aficionándolos al trabajo y a las costumbres blandas y benéficas! Ellos procuraban que la humanidad olvidase las atrocidades de los conquistadores de América. $(1817: 10)$

A pesar de su apego ostensible a las ideas de Rousseau -apego que lo habría conducido ante un tribunal del Santo Oficio en 1809 y a redactar su Catecismo de los patriotas en 1813-, Henríquez no presenta a sus omaguas como si fuesen "buenos salvajes". Sus indígenas no sólo viven en sociedad sino que conocen ya las "ventajas" de la "civilización" -europea, claro está- gracias a los inquietos misioneros de la Compañía de Jesús. Pero además, en su tribu, el Cacique había llevado a la práctica el método lancasteriano de enseñanza que el fraile había anunciado en su artículo sobre los araucanos y que Bolívar quiso imponer poco después en Venezuela, contratando al propio Joseph Lancaster : para el pedagogo inglés, cada alumno debía convertirse a su vez en un docente encargado de transmitirle un saber a sus semejantes (Henríquez 1817 : 31). Por otra parte, tanto el cacique omagua, como su cuñado, Yari, exhiben una particular predilección por la revolución norteamericana (la segunda obra teatral de Henríquez, La inocencia en el asilo de la virtud, igualmente rechazada por la Sociedad del Buen Gusto, transcurría en la ciudad de Filadelfia, cuna de la Declaración de Independencia). Durante su juventud, el Cacique había vivido con los cuáqueros de Filadelfia, mientras que Yari, educado por las mismas personas que formaron a Henríquez en Lima, se presenta como un seguidor de Thomas Jefferson en una indignada diatriba contra las autoridades españolas :

YARI. - ¡Pérfidos! ¡Y los americanos siempre crédulos y confiados! ¡Llamarlos a ustedes rebeldes! ¿Con que nuestras tribus serán rebeldes porque no se dejan despedazar por los tigres y los osos ? Luego será preciso declarar rebelde a la naturaleza, de quien recibimos el instinto de no dejarnos oprimir ; a la naturaleza, que nos inspira el deseo de la felicidad. El corazón humano está en un movimiento continuo anhelando por verse libre y dichoso. Las pretensiones de la España están en contradicción con la naturaleza. (1817:17)

Mientras que Diego Shkinere concluye la obra con esta alocución :

Aquí no hay tiranos ni perseguidores. Estáis en el asilo de la libertad, entre los hombres de la razón y de la naturaleza, en el seno de la filantropía. Acordaos de la Pensilvania, y creed que ponemos aquí los cimientos de una nueva Filadelfia. (1817: 38)

No hay ningún vitalismo en estas declaraciones : esta naturaleza no representa "la fuerza nueva y virgen de América" (Hurtado 1997 : 47) sino la antigua tradición del derecho natural en la versión de Locke y Jefferson. De modo que la supremacía europea se deniega como tal : ya no se trata, en el drama del fraile, de un pueblo sometido a los valores y las costumbres de otro sino de un pueblo que liberaría su "verdadera naturaleza", presuntamente reprimida, hasta las revoluciones, por la opresión española. Ya no se trata, en el discurso del fraile, de una minoría que le impone su cultura a las demás sino de una minoría que libera, supuestamente, la naturaleza humana en todas. Y esto explicaría por qué, durante las revoluciones de emancipación, los criollos se convirtieron en la parte que representa al todo o, para emplear una expresión de Marx, en el “representante general" de la sociedad entera (1971: 90). 


\section{Conclusión}

31 Henríquez no estaba proclamando en su obra la creación de una nueva raza, como lo harían más tarde algunos positivistas. No pensaba en un "crisol" o una "raza cósmica" sino más bien en el estatuto político de esas alianzas entre "familias" americanas. Nadie ignora, en efecto, hasta qué punto las uniones entre las casas reales tuvieron un papel central en la política europea a lo largo de los siglos. Pero el antropólogo francés Pierre Clastres observaba el mismo fenómeno en las culturas amazónicas y lo explicaba diciendo que había "intercambio de mujeres" porque, "como hay enemigos, es preciso procurarse cuñados", es decir, aliados (2001 : 209). La expresión española "hermano político" resume perfectamente la naturaleza de este vínculo. Por eso un indígena melanesio se había sorprendido mucho cuando Margaret Mead le preguntó por qué no se había casado con una de sus propias hermanas : el problema, para él, no pasaba tanto por la transgresión moral del incesto como por la evidente desventaja de verse privado así de parientes "por alianza" (1976 : 181). El antropólogo finlandés Edward Westermarck contaba que cuando una tribu berebere entraba en guerra con otra, solicitaba el auxilio de sus vecinos enviándoles grupos de jóvenes solteras lo suficientemente agraciadas como para regresar a los pocos días montadas en mulas, suntuosamente vestidas y escoltadas por sus flamantes esposos : los guerreros requeridos (1921 : 290). Y basta con observar las alianzas en el seno de cualquier comunidad para comprobar que los connubios y concubinatos siguen consolidando la solidaridad entre ciertos grupos sociales.

Cada cultura combina de diferente manera los principios de exogamia y endogamia: algunas casan a sus vástagos con miembros de otra familia, pero del mismo clan, otras prefieren establecer alianzas entre clanes diferentes, pero en el seno de una misma casta, muchas toleran incluso las uniones con los miembros de otros pueblos, pero se muestran estrictamente endogámicas en lo relativo, por ejemplo, a las clases o a las religiones. Antes de las revoluciones, la política matrimonial de los criollos tendía a reproducir las alianzas en el interior de la casta española (peninsular y americana) ; después seguirían privilegiando las alianzas en el interior de su propio clan aunque el mestizaje prosiga.

La Camila de Camilo Henríquez ponía en escena el dilema corneliano de la minoría criolla entre su alianza americana y su filiación europea : a diferencia de lo que ocurrió en África o en Asia, las revoluciones de independencia de las repúblicas americanas, tanto al norte como al sur, fueron encabezadas por los descendientes de los propios conquistadores y colonizadores. De modo que el dilema de esta minoría se encuentra estrechamente ligado a su posición política de primus inter pares dentro de la coalición popular hispanoamericana de la emancipación. Como lo dice el fraile chileno con nitidez meridiana : la condición para que la igualdad entre los americanos exista, consistió en que todos aquellos que no son criollos adopten los valores y las costumbres de los criollos. Dicho de otra manera, la condición para que la alianza entre las minorías americanas funcionara, fue que una de esas minorías se volviera hegemónica o mayoritaria. Baste con recordar que los gentilicios criollo e hispanoamericano, que aludían a una estrecha minoría social antes de las revoluciones, pasaron a convertirse en una denominación general después. Los criollos resolvieron el dilema trágico de su propia revolución evitándolo, es decir, transfiriéndoselo a las demás comunidades, para que cada una de ellas se encontrase con la disyuntiva de optar entre una fidelidad a sus tradiciones y esa taimada sumisión a la minoría hegemónica que se llamaría modernización. 


\section{BIBLIOGRAFÍA}

Aisemberg, Alicia. “Teatro, empresarios y actores”. Pellettieri, Osvaldo (dir.). Historia del teatro argentino en Buenos Aires I. Buenos Aires : Galerna, 2005, pp. 159-173.

Amunátegui, Miguel Luis. Camilo Henríquez. Santiago de Chile : Imprenta Nacional, 1889.

Badiou, Alain. Petit manuel d'inesthétique. Paris : Seuil, 1998.

Bosch, Mariano G. Historia de la ópera en Buenos Aires. Origen del canto i la música. Buenos Aires : Imprenta del Comercio, 1905.

Bosch, Mariano G. Historia del teatro en Buenos Aires. Buenos Aires : Establecimiento tipográfico El Comercio, 1910.

Clastres, Pierre. Investigaciones en antropología política. Barcelona : Gedisa, 2001.

Durán Cerda, Julio. «El teatro en las tareas revolucionarias de la independencia de Chile ». Santiago de Chile : Anales de la Universidad de Chile ${ }^{\circ}$ 119, 1960, pp. 227-235.

Fuentes Barragán, Antonio. “Mujer y mestizaje : traspasando fronteras étnico-sociales en el Buenos Aires colonial” [En línea], Débats, octobre 2012.

Funes, Deán Gregorio. Ensayo de la historia civil del Paraguay, Buenos-Ayres y Tucumán II. Buenos Aires : Imprenta de M.J. Gandarillas, 1816.

Henríquez, Camilo. La Aurora de Chile, 1812-1813. Reimpresión paleográfica a plana y renglón. Santiago de Chile : Imprenta Cervantes, 1903.

Henríquez, Camilo. La Camila o la Patriota de Sud-América. Buenos Aires : Imprenta Benavente y Cía, 1817.

Hurtado, María de la Luz. Teatro Chileno y modernidad : identidad y crisis social. Irvine : Ediciones de Gestos, 1997.

Keeding, Ekkehardt. La revolución en las tablas : Quito y el teatro insurgente 1810-1817. Quito : Fonsal, 2009.

Lavallé, Bernard. « Les tensions ethniques dans les familles péruviennes coloniales ». Paris : CLIO, Histoire, femmes, société $\mathrm{n}^{\circ}$ 27. 2008, pp. 135-151.

Marx, Karl. Critique de la philosophie du droit de Hegel (édition bilingue). Paris : Aubier, 1971.

Mead, Margaret. Macho y Hembra. Buenos Aires : Editorial Alfa, 1976.

Rípodas Ardanaz, Daisy. El matrimonio en Indias : realidad social y regulación jurídica. Buenos Aires : Fundación para la Educación, la Ciencia y la Cultura, 1977

Rodríguez Castelo, Hernán. « La obra de teatro que se escribió tras el 2 de agosto trágico ». Quito : Boletín de la Academia Nacional de Historia n 184. 2010, pp. 87-93.

Scavino, Dardo. Narraciones de la independencia. Arqueología de un fervor contradictorio. Buenos Aires : Eterna cadencia, 2010.

Senor, María Selva. “'El azar y la necesidad'. Elite y elecciones matrimoniales en Buenos Aires, 1776-1820”. Salta : Andes n 16, 2005. 
Sografi, Antonio Simeoni et Cimarosa, Domenico. Gli Orazi e i Curazi. Roma : Librettidopera, 2002.

Torres Tenorio, Camilo. “Memorial de Agravios”. Romero, José Luis (ed). Pensamiento político de la emancipación I. Caracas : Biblioteca Ayacucho, 1979.

Ulloa, Antonio de y Juan y Santicilia, Jorge. Noticias secretas de América. Madrid : Editorial América, 1918.

Urquiza Almandoz, Oscar. "El teatro en Buenos Aires en la época de la emancipación”. Kansas : Latin American Theatre Review, Volume 10, Number 2, 1977, pp. 11-28.

Villegas Morales, Juan. Historia Multicultural del teatro y de las teatralidades en América Latina. Buenos Aires : Galerna, 2005.

Westermarck, Edward. The History of the Human Marriage. London : MacMillan, 1921.

\section{RESÚMENES}

A través del dilema corneliano entre la lealtad a la familia de sangre o a la familia política, $L a$ Camila o la Patriota de Sud-América del fraile Camilo Henríquez pone en escena las contradicciones de la minoría criolla durante las revoluciones de la independencia.

À travers le dilemme cornélien entre la fidélité à la famille de sang ou à la famille par alliance, $L a$ Camila o La Patriota de Sud-América du moine Camilo Henríquez met en scène les contradictions de la minorité criolla pendant les révolutions de l'indépendance.

Through the ethical dilemma between the loyalty to the blood family or to the political family, $\mathrm{La}$ Camila o la Patriota de Sud-América, written by the friar Camilo Henríquez, stages the contradictions of the Creole minority during the Americans revolutions.

\section{ÍNDICE}

Mots-clés: criollos, indiens, révolutions, mariages, hégémonie

Palabras claves: criollos, indios, revoluciones, matrimonios, hegemonía

Keywords: Creoles, Indians, revolutions, marriages, supremacy

\section{AUTOR}

\section{DARDO SCAVINO}

Université de Pau

dardo.scavino@orange.fr 